\title{
Elderly travel frequencies and transport mode choices in Greater Rotterdam, the Netherlands
}

\author{
Lars Böcker ${ }^{1}$ Patrick van Amen² Marco Helbich $^{2}$
}

Published online: 20 February 2016

(c) The Author(s) 2016. This article is published with open access at Springerlink.com

\begin{abstract}
Demographic ageing is a key societal challenge in Europe as well as in many other western and non-western societies. A crucial dimension concerns elderly daily mobility patterns. While still partaking fewer and shorter trips than younger generations, today's elderly have been found increasingly (auto)mobile. Although the elderly benefit from the independence, freedom of movement, and social inclusion, concerns may rise regarding the environmental and accessibility impacts of this induced mobility. The present study adds to the expanding literature on elderly mobility, an integrated analysis of the effects of socio-demographic, health, trip, spatial and weather attributes on elderly mobility. Utilizing travel diary data for Greater Rotterdam, The Netherlands, trip frequencies and transport mode choices of the elderly are analysed by means of zero-inflated negative binomial models as well as multinomial logit regression models, and contrasted to the non-elderly subpopulation to explore (dis)similarities. While the results show common determinants, the models also highlight important differences in the magnitude of the estimated coefficients and factors only influencing transport patterns for the elderly. Embedded in the context of an aging population, the empirical findings assist policymakers and planners in several respects: For transportation plans and programs it is critical to recognize mobility needs of the elderly. As the seniors are becoming increasingly automobile, the results call for strategies to encourage older people to use more physically active and environmentally friendly transport modes such as public transport, walking and cycling.
\end{abstract}

Keywords Elderly · Mobility · Transport mode choice - Urban form · Weather . Netherlands

Marco Helbich

m.helbich@uu.nl

1 Department of Sociology and Human Geography, Faculty of Social Sciences, University of Oslo, Moltke Moes vei 31, 0851 Oslo, Norway

2 Department of Human Geography and Spatial Planning, Faculty of Geosciences, Utrecht University, Heidelberglaan 2, 3584 CS Utrecht, The Netherlands 


\section{Introduction}

Ageing is one of the key societal challenges worldwide, and especially in Europe where the majority of baby-boomers are soon reaching their retirement age (European Commission 2014). For the Netherlands the share of the population aged 65 or above is expected to rise from $16 \%$ in 2010 to between 23 and $29 \%$ in 2040 (Netherlands Environmental Assessment Agency 2013). Besides well-documented social and economic implications (e.g. Harper 2014), ageing also has significant consequences for the transport sector. Although elderly have still been found to travel less often and less far than younger age groups (e.g. Collia et al. 2003), they have become increasingly mobile over the last decades, because of increased income levels, better health, and more active lifestyles (e.g. Marrattoli et al. 2000) — a trend which is likely to proceed (e.g. Arentze et al. 2008). Moreover, the elderly rely, less than before, on public transport and more on the car (e.g. Noble 2000; Rosenbloom 2001; Alsnih and Hensher 2003; Donaghy et al. 2004). As a consequence, some scholars find that the elderly constitute the fastest growing segment of the driving population, both in terms of license rates and kilometres travelled (e.g. Okola and Walton 2003; Banister and Bowling 2004).

While studies emphasise the importance of the elderly's mobility for their social inclusion (e.g. Ravulaparthy et al. 2013) and quality of life (e.g. Delbosc and Currie 2011; Haustein and Siren 2014), concerns are being raised regarding the implications of this induced automobility to society, in terms of greenhouse gas emissions, environmental pollution and congestion (e.g. Rosenbloom 2001; Banister and Bowling 2004). In the Netherlands, Jorritsma and Kalter (2008) have found that an increase in elderly out-ofhome activities has led to a $3 \%$ growth in overall distances travelled. In addition, increased car dependency amongst the elderly may have negative health impacts resulting from a lack of physical activeness (e.g. Oxley and Whelan 2008; Kemperman and Timmermans 2014), which, especially at older age, is vital to physical (e.g. Visser et al. 2002) and mental health (e.g. Binder et al. 2002; Strawbridge et al. 2002).

This societal relevance of elderly mobility has led to a rapid recent expansion of scientific literature. Research conducted so far investigates the influence of socio-demographic factors(e.g. Kim and Ulfarsson 2004; Rosenbloom 2004; Li et al. 2012; Mercado and Páez 2009; Schmöcker et al. 2008; Hjorthol et al. 2010; Kim 2011, Yang et al. 2014a), spatial environments (e.g. Schwanen et al. 2001; Waldorf 2003; Banister and Bowling 2004; Michael et al. 2006; Hess 2009; Borst et al. 2009; Gómez et al. 2010; Hall and McAuley 2010; Kemperman and Timmermans 2014), and policies (e.g. Mercado et al. 2010) on elderly activity patterns, trip frequencies, transport mode choices, and physical activeness. Although all of these studies provide essential contributions to the field, several shortcomings can be identified. First, while most studies focus on just one type of elderly travel behaviour (e.g. only trip making or mode choice), only few look at the effects on multiple behavioural aspects simultaneously (e.g. Schwanen et al. 2001; Collia et al. 2003; Arentze et al. 2008). Second, while many existing studies look at elderly populations exclusively, fewer studies conduct comparisons to younger age cohorts (e.g. Schwanen et al. 2001; Rosenbloom 2004; Páez et al. 2007; Mercado and Páez 2009; Hjorthol et al. 2010). Third, with regard to the effects of spatial environments, previous research is often limited to the effects of address density or the availability of different infrastructures, whereas other components of the built and natural environment, such as land use patterns and building diversities, are often not considered (for an exception see Kemperman and Timmermans 2014). Moreover, in contrast to static spatial attributes, elderly mobility studies scarcely address dynamic natural environmental conditions including 
daylight, seasonality and weather (exceptions are Hjorthol 2013; Yang et al. 2014a). This is surprising given that elderly are considered as more sensitive or vulnerable to weather than younger age groups (e.g. Díaz et al. 2002; Tuomaala et al. 2013; Böcker et al. 2014).

In order to address these shortcomings, this research aims to provide an integrated analysis of the effects of socio-demographics, health attributes, trip characteristics, spatial environments, and normal and extreme weather on elderly as compared to non-elderly trip making and transport mode choices. Daily trip frequencies and transport mode choices of the elderly are analysed in zero-inflated negative binomial and multinomial logistic regression models, and are contrasted with the non-elderly subpopulation to explore (dis)similarities. This study draws on Greater Rotterdam (The Netherlands) stated adaptation data and travel diary data linked to spatial and weather attributes. The remainder of this paper is organized as follows. "Literature review" section reviews the literature concerning transport-related factors. Next, the research design is introduced in "Research design" section. "Results and discussion" section presents major results while "Conclusion" section highlights key conclusions and discusses possible implications.

\section{Literature review}

To investigate the potential effects of ageing on mobility patterns, several mostly westernworld studies have compared elderly trip making and transport mode choices to younger generations. American (e.g. Collia et al. 2003; Kim and Ulfarsson 2004; Hess 2009; Kim 2011), Canadian (e.g. Newbold et al. 2005; Mercado and Páez 2009; Páez et al. 2007), and Australian (e.g. Currie and Delbosc 2009) studies, find that elderly have similar car dependent transport mode shares than younger generations, but that they make fewer and shorter trips. However, it is increasingly emphasised that levels of mobility differ not only between the elderly and non-elderly, but also within elderly populations. Alsnih and Henscher (2003) from a literature review, conclude that it is useful to distinguish between younger (65-75) and older (75+) elderly, because this marks the age in which health limitations become more prominent. Hildebrand (2003), (Haustein 2012) and Siren and Haustein (2013) segment elderly mobility in more diverse ways based on their dependences of, and their attitudes and lifestyles regarding, mobility in general and different transport modes in particular.

In search for explanatory factors for within-elderly heterogeneity in mobility behaviours scholars often highlight socio-demographic profiles. Páez et al. (2007) and Newbold et al. (2005) respectively find that female and unemployed elderly perform fewer and shorter trips than their male and employed counterparts. The latter can be attributed to noncommute trips being generally shorter in distance. Páez et al. (2007) add that having a driver's license and access to a car positively affects elderly trip frequencies. Kim and Ulfarsson (2004) report that elderly with higher incomes are more likely to drive or carpool. Besides, Kim (2011) finds that ethnic minority elderly women make fewer trips than the average elderly, which could indicate an inhibiting effect of belonging to an ethnic minority. Hess (2009) elaborates on the role of household types, finding that single household elderly are more likely to use public transport.

In the United Kingdom, Li et al. (2012) explored transport mode choices of the elderly and confirm that the private car is the most commonly used transport mode. However, unlike most of the earlier mentioned North American and Australian studies, their results indicate that the share of car use decreases at higher ages. Moreover, Schmöcker et al. 
(2008) investigated shopping trip transport mode choices amongst a sample of older and disabled people in London, UK. As with the other studies, car use appeared to be the most important transport mode. With respect to gender, both Li et al. (2012) and Schmöcker et al. (2008) find that elderly women make fewer trips than elderly men, and (if they do) rely less on car and more on bus travel. Schmöcker et al. (2008) report in addition that higher income has a negative effect on public transport use. Similar findings have been found in other parts of Europe. In a study amongst Danish, Norwegian and Swedish elderly, Hjorthol et al. (2010) confirm earlier findings that women, as well as those who own no driver's license, perform fewer trips in general and fewer trips by car in particular. With regard to car ownership, the authors notice that elderly men are more likely to keep their cars when they are older compared to elderly women.

Also in the Netherlands, the context of this study, elderly mobility received some attention. Schwanen et al. (2001) analyse elderly leisure trips, and approve the general picture that the elderly travel less often than younger age cohorts. Of all transport modes the elderly most commonly use the private car, although elderly car usage (as well as walking and cycling) decreases with older age to the benefit of public transport. Additionally, elderly women are more likely to use the public transport, whereas lower income and unemployed elderly are more likely to walk and cycle. Highly educated elderly were found to conduct more trips in general, more trips further away from home, and a larger share by public transport. Finally, having a driver's license and (even more so) owning a car enhances car use compared to all other transport modes. In a more recent Dutch study Van den Berg et al. (2011) analyse elderly social trip frequencies. In contrast to earlier studies, no age effect is reported. Full-time employed and lower educated elderly perform fewer social trips. Congruent with Schwanen et al. (2001), car owners and lower educated elderly perform (social) trips more likely by car.

In addition to the effects of socio-demographic factors, elderly mobility studies have investigated the role of spatial contexts. Residential environments may be of particular importance to the elderly, not only because the elderly travel overall less far from home than younger age groups (Collia et al. 2003), but also because their spatial needs are more demanding - e.g. safe crossing points, resting places, equal pavement surfaces (Metz 2003). When analysing the role of spatial contexts on elderly mobility, most studies look at the degree of urbanisation. In a German study, Scheiner (2006) finds that the degree of urbanization has no effect on elderly out-of-home leisure activity frequency, diversity or distance, as well as no effect on unfulfilled elderly activity wishes or leisure satisfaction. Others however, do find effects. In their London study, Schmöcker et al. (2005) find that elderly in higher density residential environments travel shorter distances. Schwanen et al. (2001) point out that elderly in the four largest Dutch cities in the Randstad Holland travel more often than those outside this metropolitan region. Additionally, elderly in urban residential environments are more likely to use the public transport compared to travelling by foot, car and especially bicycle. In contrast, in a Danish study Figueroa et al. (2014) find that elderly substitute car use by public transport less in higher densities than non-elderly. However, Schwanen and others in their Dutch study point out that residential context mostly matters when elderly do not own a car. However, when they do, they are most likely to travel by car regardless of the environment. Kemperman and Timmermans (2014) find that elderly in Dutch urban areas are more likely to walk and less likely to cycle, than those in rural areas. Additionally, they consider the impact of green space, concluding that green residential environments stimulate both walking and cycling amongst the elderly. Other studies find that elements associated with walk ability have positive effects on elderly physically active travel. For instance, the presence of car free zones (Gómez et al. 
2010), pavements, dwellings, gardens and shops (Borst et al. 2009), and the amount of walking paths in the direct vicinity to the home (Hall and McAuley 2010), all have positive effects on elderly walking. As an exception, Michael et al. (2006), report no effect of walking path density on the amount of elderly walking trips made within the neighbourhood.

Existing studies address spatial contexts predominantly from a static point of view. In contrast, only few studies on elderly mobility have explored dynamic natural processes that could have profound spatial ramifications (i.e. seasonality, weather). This limited attention for weather conditions is surprising, given the elderly's higher sensitivity to cold and hot weather conditions compared to younger people (e.g. Díaz et al. 2002; Tuomaala et al. 2013). The limited evidence includes a study from the Netherlands by Yang et al. (2014a), who cluster elderly based on their travel patterns. They find that some have season-specific travel patterns, such as driving or being driven by car in winter, while making use of active modes in other seasons. Also for the Netherlands, Böcker et al. (2014) find that elderly experience cold weather as colder than younger age groups which negatively affects the elderly's choices to walk and cycle, in comparison to motorised transport. Finally, in Norway, Hjortol (2013) investigated elderly mobility in demanding Norwegian winters. The effects of winter conditions (i.e. snow-cover, icy pavements, low temperature), proved very challenging for elderly with walking problems.

\section{Research design}

\section{Study area}

The study area is Greater Rotterdam: a mainly densely populated area with 1.2 million people (RegioAtlas 2014) in the west of the Netherlands bordering the North Sea. The rationale for selecting Greater Rotterdam is threefold: First, Greater Rotterdam will be subjected to an ageing population in the coming decade. From 2014 to 2025, the province of South-Holland, of which Rotterdam is part, expects a $27 \%$ increase of the number of people over 64 and a $40 \%$ increase of the number of people over 84 years old (Dienst Gezondheid and Jeugd 2014). Second, the area comprises rich population diversity in terms of ethnicity and socio-economic status, both amongst the elderly and non-elderly populations. Third, the diversity in the built environment across the region ranges from rural to suburban landscapes to the dense inner-city areas of Rotterdam with its modern high-rise buildings resulting in diverse travel patterns.

\section{Data}

This study draws on a travel diary dataset used previously in earlier publications (e.g. Böcker and Thorsson 2014; Helbich et al. 2014). Between August 2012 and February 2013, 945 respondents have been randomly assigned six survey days; two in summer, two in autumn and two in winter. To achieve a spatially well-balanced data, the sampling design stratifies the study area in inner-city, outer-centre, green/sub-urban and rural areas. Groups expected to have lower response rates including the elderly and ethnic minorities have been oversampled. With the exception of underrepresentation of lower educated and people with a non-western ethnicity, the overall sample (elderly and non-elderly combined) represents the region's population statistics relatively well. For the present research, we have 
extracted data from 147 elderly aged at least 65 years, and contrasted these to the remaining 798 non-elderly respondents. Within this elderly subsample, women and nonwestern elderly are underrepresented, while other attributes are relatively well distributed. In our models we account for the sample bias by controlling for all socio-demographic background attributes. The remaining data about the general population serves as reference for cross-comparisons.

In addition to transport-related variables (e.g. trip distance, motives), data about individual (e.g. age, gender), household (e.g. household income, number of cars) and healthrelated attributes are collected through questionnaires. Health-related attributes may be key factors in explaining elderly mobility. Data on length and weight are collected and used to calculate BMI values, which are categorised as "obese" if above or equal to 30. Moreover, information is collected on whether people are constraint by some form of disability in daily life (and if so, by which type). Respondents report mostly physical disabilities (including cardiovascular and muscular diseases, diabetes or visual impairment), but some also indicate mental health issues, such as burnout and depression. Because of the limited share of disabled respondents and the wide range of reported disabilities, we have analysed disabilities as one single category.

In a subsequent step, respondent's residential addresses are geocoded via Dutch cadastral data 'Basisregistraties Adressenen Gebouwen 2012' (BAG). Utilizing a geographic information system, several variables describing the built and natural environment are computed. Hereto a $100 \mathrm{~m}$ grid is superimposed on the study area and for each cell the following three indicators are computed: First, address density comprises the combined number of residential and commercial addresses per cell, which is later rescaled as the number of addresses per $\mathrm{km}^{2}$. Second, the building usage diversity refers to the mix of building usages (i.e. office, shop, public service, etc.) and is operationalized based on the Shannon entropy index. A value of 0 indicates a single building usage; higher values represent buffers in which building usages are more diverse. Third, based on data from 'Landelijk Grondgebruiksbestand 6' green spaces are extracted referring to the surfacearea percentage of all combined green land uses (e.g. parks, forests), except agriculture. Subsequently, a circular buffer (see Wong et al. 2011) of $300 \mathrm{~m}$ around each residential location is computed and intersected with the averaged gridded environmental variables.

Finally, during the length of the study period, daily meteorological data for the nearest weather station ('Zestienhoven' $51^{\circ} 57^{\prime} \mathrm{N}, 4^{\circ} 27^{\prime} \mathrm{E}$ ) are obtained from the Royal Dutch Meteorological Institute (2013). Following Helbich et al. (2014), the following daily weather variables are considered: (a) daily maximum air temperature in ${ }^{\circ} \mathrm{C}$, (b) precipitation sum in $\mathrm{mm}$, (c) average wind speed in $\mathrm{m} / \mathrm{s}$, and (d) a dummy variable indicating snow cover. Table 1 presents key descriptive statistics for all variables for both elderly and nonelderly population. The influence of marginally occurring (extreme) weather events like heat, frost, snow/ice, extreme rain and storm on elderly and non-elderly mobility has been investigated via supplementary descriptive analyses, based on stated adaptation questions in the survey. This analysis is restricted to errands and leisure trips, as (unlike work trips) both elderly and non-elderly commit these types of trips.

\section{Multivariate modelling techniques}

Two multivariate analyses are performed to estimate the determinants of elderly trip frequencies on a daily level and transport mode choices on a trip level. Both analyses consist of separate models for the elderly and non-elderly age-cohorts. The first analysis investigates count data on the number of trips per person per day. Use of a standard Poisson 


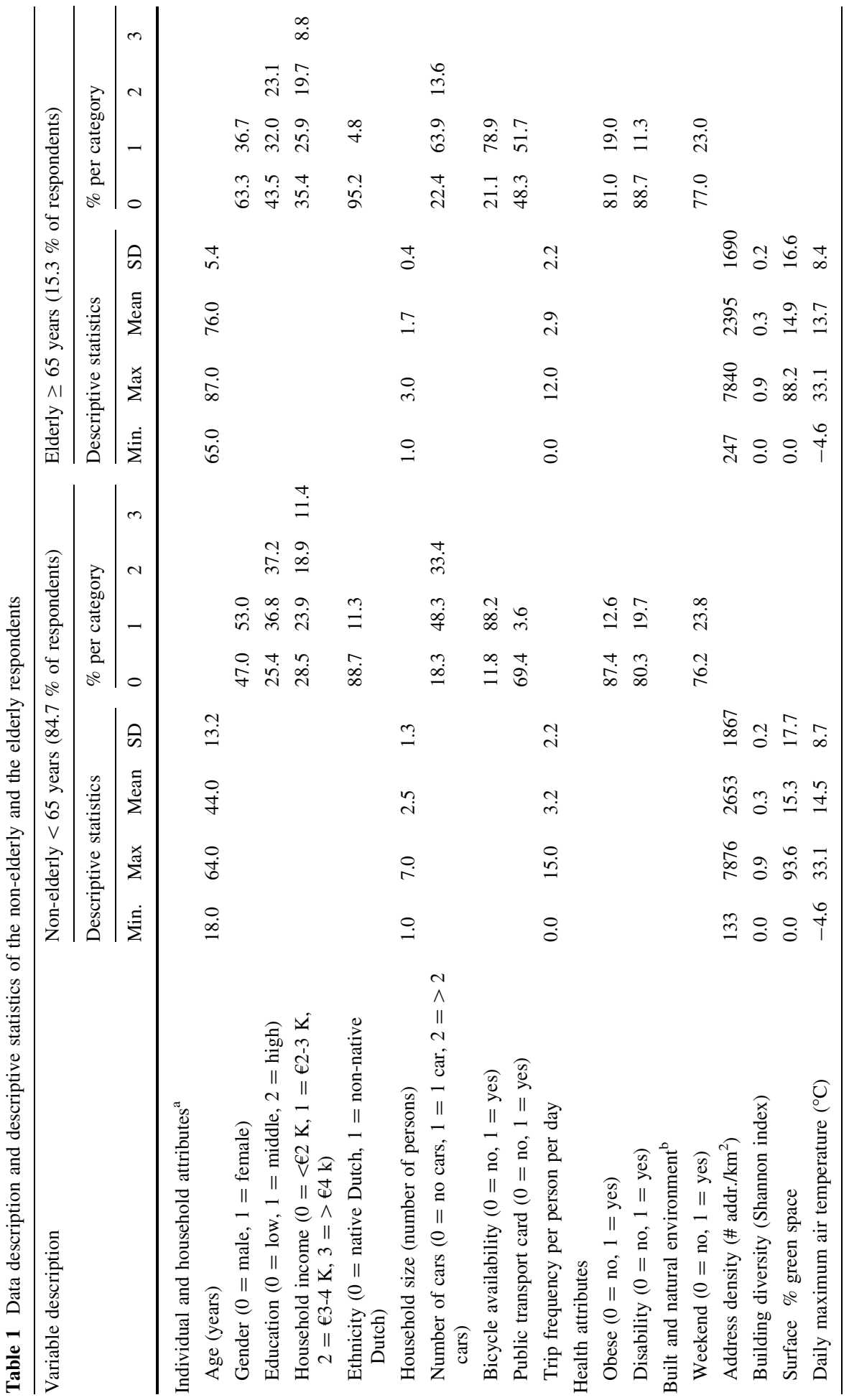




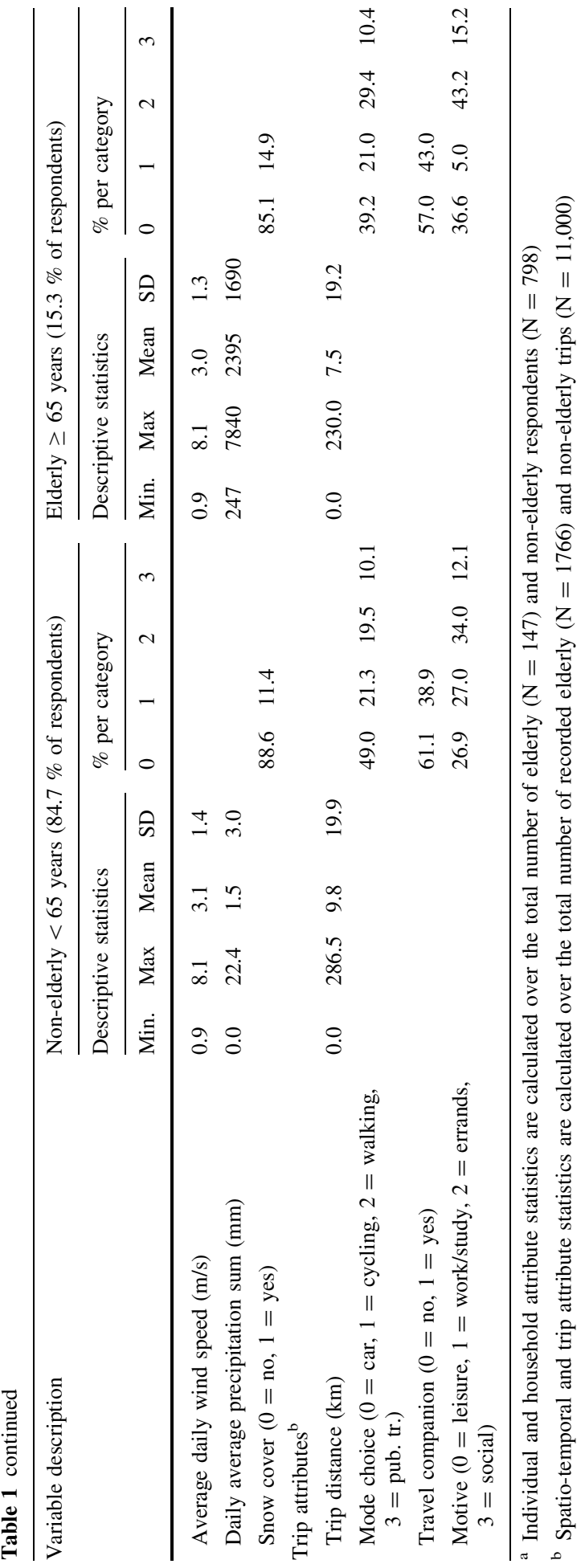




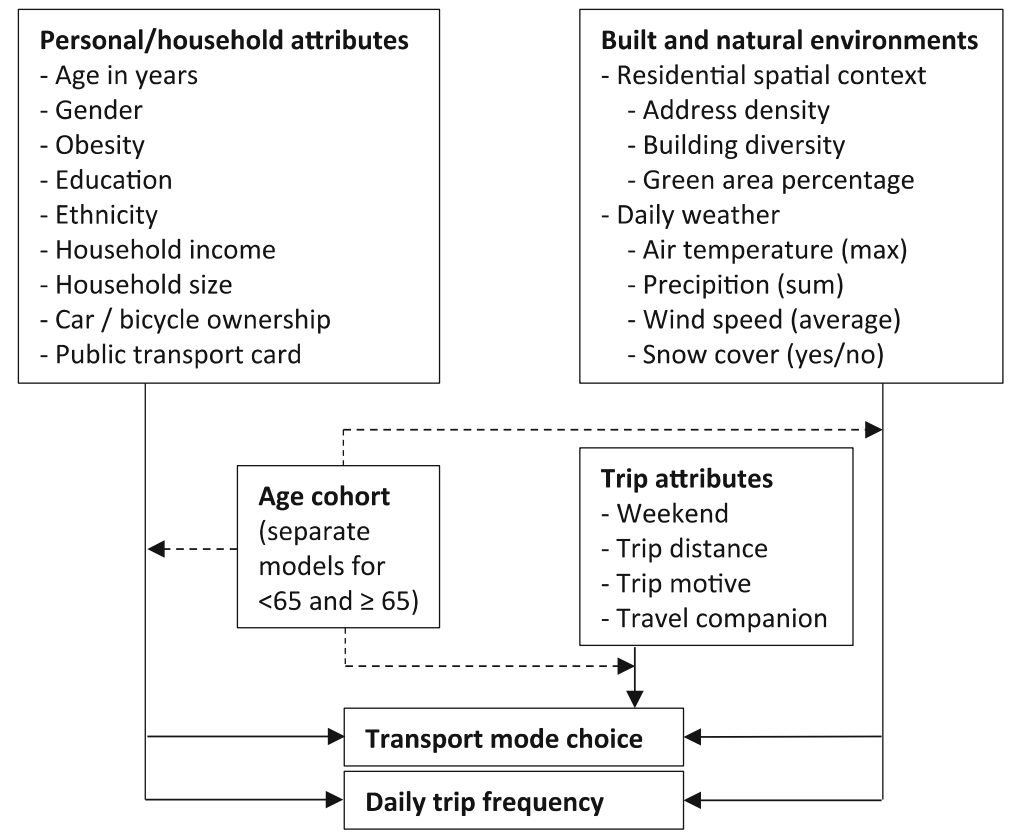

Fig. 1 Conceptual model

regression model has been rejected here because the variance in trip frequency exceeds its mean, which provokes an estimation bias and inconsistent estimates (Lord and Mannering 2010). To deal with the issue of over-dispersion a negative binomial model is recommended, even though an excess of zeros in the data challenges the analysis. For example, strong precipitation during a day might resign people from outdoor trips and they stay at home. While restricting the analysis to $\geq 1$ trip or re-classifying the number of trips to a binary variable would avert related complications, it would consequence an unacceptable loss of information. To consider the entire information, we estimate a zero-inflated negative binomial model (ZINB; Lord and Mannering 2010). For model evaluation, the ZINB model is compared with the standard negative binomial model through the Vuong (1989) test statistic.

The second analysis investigates transport mode choice (i.e. automobile, cycling, walking, and public transport) on a trip level in a multinomial logit regression analysis. The car is chosen as the reference category, because from a policy perspective it is particularly interesting to see how each of the alternative transport modes compares to the car. Both analyses are based on observations (trips or day records) that are non-independent, because they are hierarchically nested within respondents. To relax the requirement of independent observations, we adjust for within-cluster correlations by estimating robust standard errors for observations clustered within one respondent (Wooldridge 2002). ${ }^{1}$ Figure 1 presents the research design in a conceptual model.

\footnotetext{
1 Via the Stata software's "vce-cluster" command.
} 


\section{Results and discussion}

\section{Number of trips}

To investigate which factors influence elderly trip frequencies in comparison to younger age cohorts, Table 2 reports on the zero-inflated negative binomial model outcomes of daily trip frequencies, based on the 625 day records by elderly people and 3659 days records by younger age cohorts. The zero-inflated model was chosen over the regular negative binomial model based on the Vuong test, which indicated a significant

Table 2 Results for the ZINB models on the number of trips per person per day

\begin{tabular}{|c|c|c|c|c|}
\hline & \multicolumn{2}{|c|}{ Elderly $(\mathrm{N}=625)$} & \multicolumn{2}{|c|}{ Non-elderly $(\mathrm{N}=3659)$} \\
\hline & Coef. & $z$-value & Coef. & $z$-value \\
\hline Intercept & 0.795 & 0.95 & 0.751 & 5.45 \\
\hline \multicolumn{5}{|l|}{ Individual and household attributes } \\
\hline Age & -0.007 & -0.76 & $0.007 * * *$ & 4.24 \\
\hline Male (ref $=$ female) & 0.044 & 0.33 & $-0.010 * *$ & -2.62 \\
\hline Education $^{\mathrm{a}}(\mathrm{ref}=\mathrm{high})$, low & $0.209 *$ & 1.75 & $0.152 * * *$ & 2.85 \\
\hline Education middle & -0.020 & -0.17 & $0.124 * *$ & 2.47 \\
\hline Ethnicity (ref = Native Dutch), Non-Western & $-0.361 * *$ & -1.97 & $-0.120 * *$ & -2.35 \\
\hline Household income (ref $=<2000 €), 2000-3000 €^{\mathrm{a}}$ & -0.134 & -1.06 & -0.068 & -1.34 \\
\hline Household income $>3000-4000 €$ & -0.089 & -0.64 & -0.054 & -0.96 \\
\hline Household income $>4000 €$ & $-0.328^{*}$ & -1.73 & $-0.172 * *$ & -2.48 \\
\hline Household size & 0.259 & 1.44 & $0.072 * * *$ & 4.76 \\
\hline Number of cars (ref $=$ no car), 1 car & -0.008 & -0.05 & -0.057 & -0.94 \\
\hline Number of cars, 2 cars or more & -0.003 & -0.01 & 0.002 & 0.03 \\
\hline Bicycle availability (ref $=$ no) & $0.429 * *$ & 2.27 & 0.057 & 0.85 \\
\hline Public transport card owner $($ ref $=$ no $)$ & 0.161 & 1.49 & -0.005 & -0.03 \\
\hline \multicolumn{5}{|l|}{ Health attributes } \\
\hline Obese $($ ref $=$ not obese $)$ & 0.117 & 1.01 & 0.001 & 0.03 \\
\hline Disability (ref = no disability) & $-0.356^{* *}$ & -2.22 & $-0.198 * * *$ & -3.10 \\
\hline \multicolumn{5}{|l|}{ Trip attributes ${ }^{b}$} \\
\hline Weekend (ref = weekday) & $-0.382 * * *$ & -4.48 & $-0.205 * * *$ & -5.19 \\
\hline \multicolumn{5}{|l|}{ Built and natural environment } \\
\hline Address density (in 1000 addr./km²) & 0.001 & 0.03 & -0.014 & -1.04 \\
\hline Building diversity (Shannon index) & -0.292 & -0.87 & 0.097 & 0.87 \\
\hline Surface $\%$ green space & -0.005 & -1.49 & $-0.002 * *$ & -2.15 \\
\hline Maximum daily air temperature in ${ }^{\circ} \mathrm{C}$ & -0.003 & -0.73 & $0.006^{* * *}$ & 3.95 \\
\hline Daily precipitation sum in $\mathrm{mm}$ & $-0.021 *$ & -1.76 & -0.004 & -1.09 \\
\hline Average daily wind speed in $\mathrm{m} / \mathrm{s}$ & -0.027 & -1.04 & -0.002 & -0.24 \\
\hline Snow cover $($ ref $=$ no), yes & $-0.240 * *$ & -2.38 & -0.027 & -0.63 \\
\hline Model quality: Wald $\mathrm{Chi}^{2} / R^{2}$ (Nagelkerke) & \multicolumn{2}{|c|}{$141.97 * * * / 0.210$} & \multicolumn{2}{|c|}{$132.82 * * * / 0.073$} \\
\hline
\end{tabular}

Signif. codes: $*<0.10 ; * *<0.05 ; * * *<0.01$

a Categories with unknown values are estimated but are not shown in the table

b Due to a daily analysis level, trip-specific attributes like motive and travel distance cannot be considered 
improvement in model fit for both subsamples (elderly: $z=1.93, p=0.027$; non-elderly: $z=1.76, p=0.039$ ). With a Nagelkerke pseudo- $R^{2}$ of 0.210 our model explains elderly reasonably well. In contrast, the non-elderly model leaves more variance in trip making unexplained (Nagelkerke pseudo- $R^{2}$ of 0.073 ). Correlation analysis rejected problems with multicollinearity between the predictors.

As shown in Table 1, the elderly travel less (2.9 trips on average per person per day) than younger age cohorts (3.2 trips per person per day). When looked at the effect of age on trip frequencies within the elderly subsample, in line with Currie and Delbosc (2009) and Páez et al. (2007), a negative effect of age can also be observed, but it cannot be statistically confirmed. Also, reduced trip frequencies amongst elderly women as found by e.g. Páez et al. (2007), Schmöcker et al. (2008) and Li et al. (2012), cannot be statistically confirmed. Nevertheless, gender differences amongst the elderly contrast with that of the non-elderly, where women are found to participate in more trips than men. When looked at the effects of education, in contrast with Schwanen et al. (2001), both elderly and nonelderly lower educated perform more trips than higher educated. For both subsamples, a similar trip-reducing effect is found with regard to the highest income $(>4000 €)$, although in line with Mercado and Páez (2009), this negative effect of high income amongst the elderly is statistically not significant. As expected, for instance as a result of chauffeuring tasks, larger households perform more trips, but also here the effect is non-significant for the elderly. An interesting finding in congruence with Kim (2011), but for the rest largely uncovered in the literature, is a statistical confirmation that non-western elderly make fewer trips than western native Dutch elderly; an effect also observed amongst younger age cohorts. Cultural differences may play a role here. In some cultures it is common practice that children take care of their parents, while in western cultures the elderly are increasingly expected to be independent. When looked at the effects of mobility resources, in contrast to some existing studies that stress the societal isolation of elderly who do not have access to a car (e.g. Ravulaparthy et al. 2013), we do not observe an effect of car ownership on trip frequency. An explanation could be that in the Netherlands the car is not as dominant as it is in other western countries. This could also explain why bicycle availability, does have a strong positive effect on elderly trip making. For non-elderly, owning a bicycle does not affect trip making significantly. It illustrates that cycling is an essential means of transport for Dutch elderly. It may also be hypothesised that (not) owning a bicycle as an elderly could be a more general indicator of (poor) health. Of the health indicators, disability has a strong negative effect on both elderly and non-elderly trip frequencies, while obesity has no significant effect.

Additionally, Table 2 shows that various spatiotemporal attributes matter for elderly and non-elderly trip making. Even though most elderly have reached retirement, they demonstrate a weekly rhythm of clearly fewer trips during weekends in comparison to weekdays. Spatial context attributes of the residential environment do not have a pronounced effect on elderly trip making. Overall, a greener neighbourhood seems to have a negative effect on the number of trips, although for the elderly this effect cannot be statistically confirmed. This negative effect could indicate that people in (attractive) green neighbourhoods stay more in and around the house or garden, while people in areas with relatively little green may report more trips for leisure.

When looked at the effects of weather a higher impact can be observed. Moreover, the effects of weather differ clearly between elderly and non-elderly. While for the non-elderly maximum daily air temperature shows a significant positive association (confirming e.g. Sabir 2011), for the elderly an opposite negative effect, although non-significant, can be observed. This could possibly indicate that, in line with studies indicating higher heat 

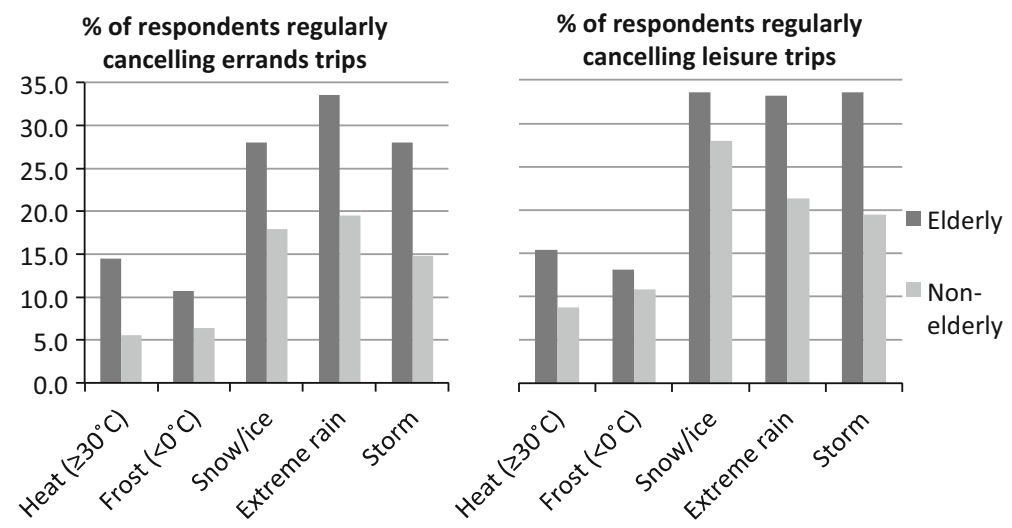

Fig. 2 Impact of extreme weather on stated trip cancelling

sensitivity amongst elderly (e.g. Tuomaala et al. 2013), warm or hot weather conditions are for the elderly a reason to stay inside. Moreover, elderly appear more sensitive to precipitation and snow cover. Both have a significant negative effect. The latter may be related to the higher risks elderly have to fall under slippery conditions (Hjorthol 2013).

Because extreme weather events are marginally occurring, their impacts on trip frequencies may be underestimated in the model. However, this does not make the impact of extreme weather less relevant, certainly not when elderly mobility is concerned. Supplementary descriptive analyses of stated adaptation data show that a larger share of elderly than non-elderly state that they cancel errands and leisure trips than non-elderly, with the occurrence of extreme weather events (Fig. 2). Snow/ice, extreme rain and storm are most disruptive, especially for the elderly. Heat has little effect on non-elderly trip making, but does keep a considerable share of elderly from making trips $(15 \%)$. Sub-zero temperatures have little effect as long as they are not combined with slippery conditions.

\section{Mode choice}

Substantial descriptive differences are between elderly and non-elderly transport mode choices (Table 1). While the non-elderly perform $49.0 \%$ of their trips by car, this is only the case in $39.2 \%$ for the elderly. For the latter, walking seems to be more important $(29.4 \%)$ than for the non-elderly $(19.4 \%)$. Explanations may include that elderly travel shorter distances $(7.5 \mathrm{~km}$ on average per trip compared to $9.8 \mathrm{~km}$ for non-elderly) and own fewer cars $(22.4 \%$ of the elderly owns no car, compared to $18.3 \%$ of the younger age cohorts). No differences between elderly and non-elderly public transport usage can be identified, however a new policy initiative to offer free public transport to elderly (RET 2015) may change this in the coming years.

In order to determine which factors influence elderly and non-elderly transport mode choices, multinomial logit regressions are estimated for both groups (Table 3). The analysis is conducted on a trip level and comprises 1766 trips for the elderly and 11,000 trips for the general population. With a Nagelkerke pseudo- $R^{2}$ of 0.518 for people below 65 years and 0.614 for people above 65 years, both models fit the data well. Correlation analysis rejected problems with multicollinearity between the predictors. 


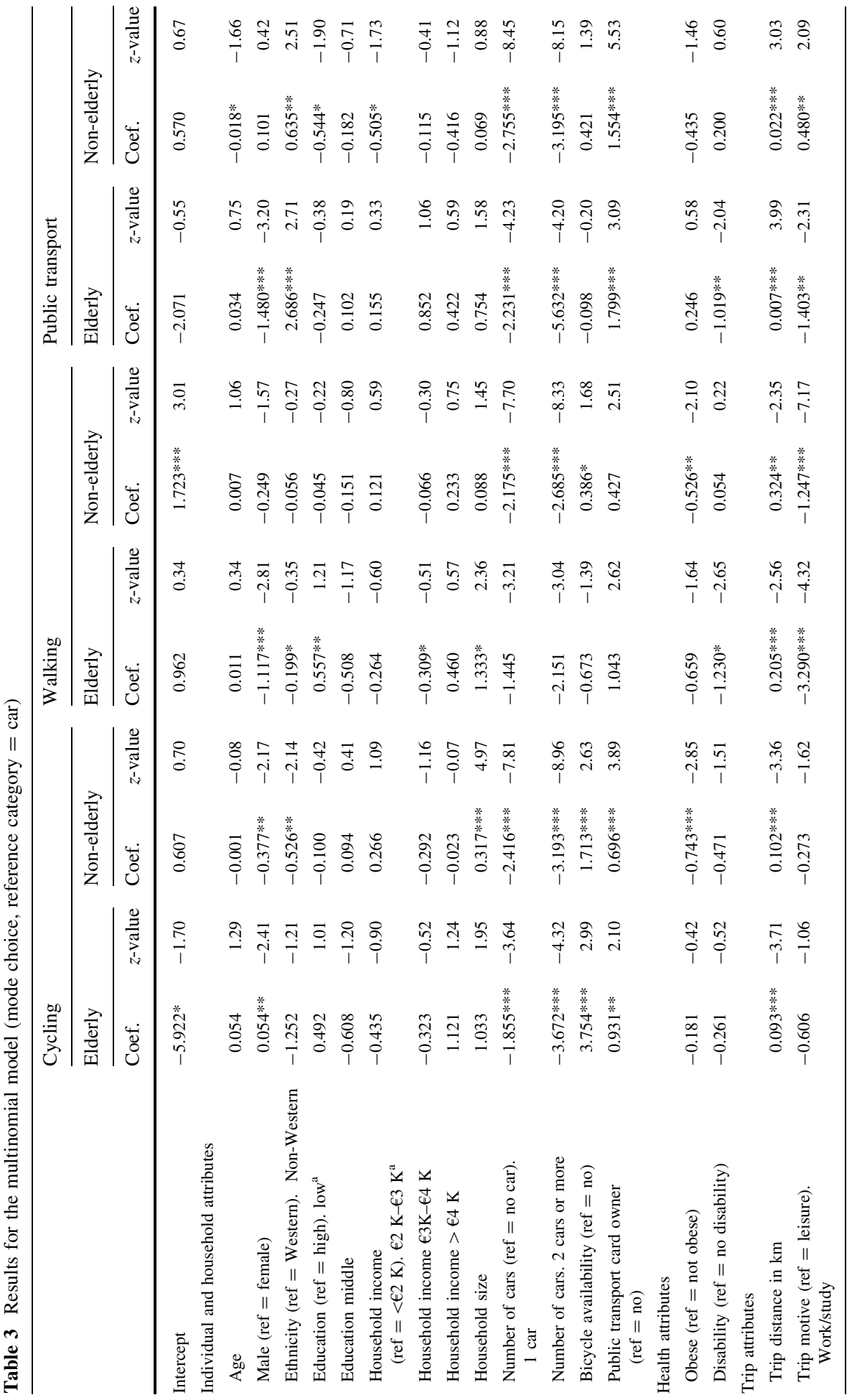




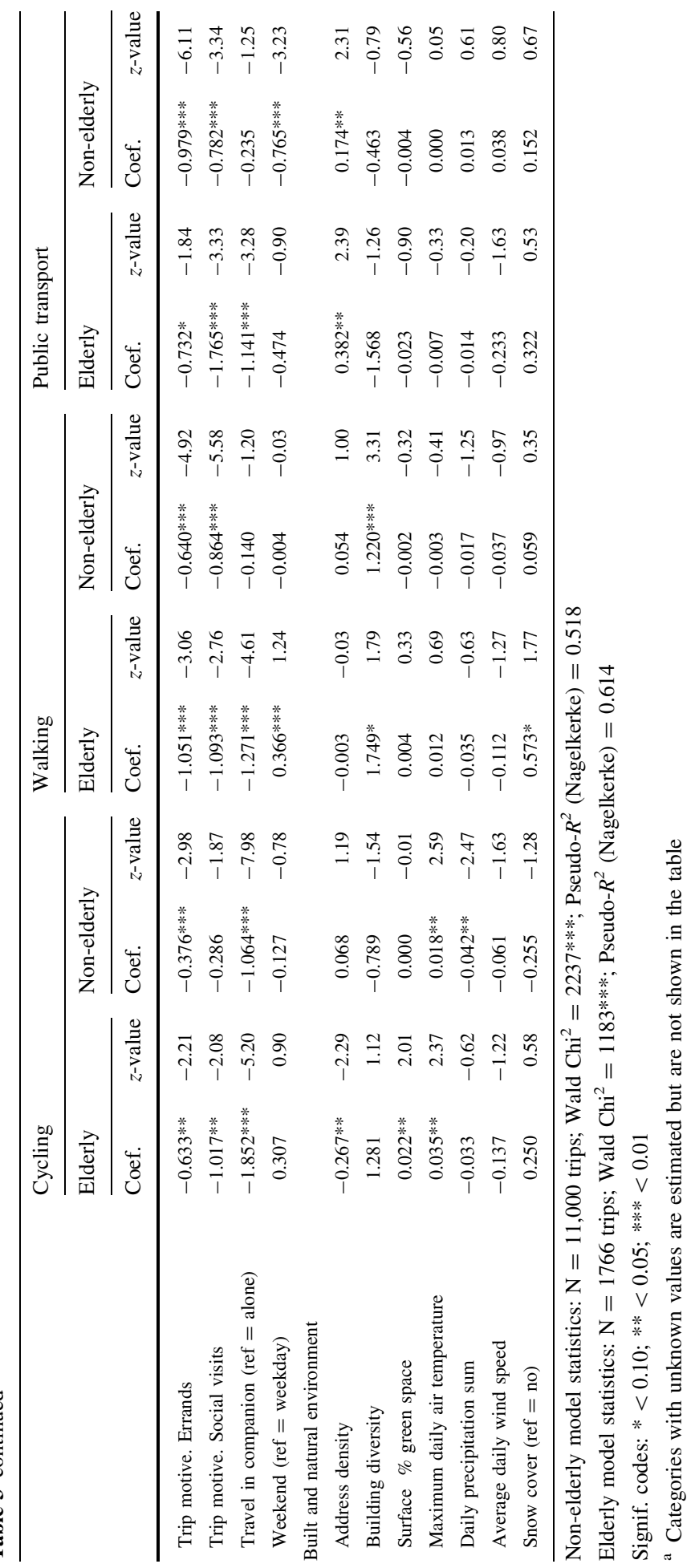


The multivariate results in Table 3 show no significant age effect on transport mode choices within the elderly and non-elderly subsamples. Other socio-demographic factors, in particular gender, exert a more prominent effect. Moreover, gender differences in transport mode choices are more important amongst the elderly than younger people. While for the non-elderly only a significant gender effect on bicycle usage can be found (women cycle more than men), when looked at the elderly, women are more dependent on walking, cycling and using the transport in comparison to the car. This confirms earlier findings by Schmöcker et al. (2008) that elderly men are more likely to take the car, and Schwanen et al. (2001) who highlight a stronger public transport dependency amongst elderly women, despite recent trends indicating an increase in women's automobility (Schwanen and Páez 2010). Ethnicity appears to be another influential socio-demographic factor. In congruence with a limited body of literature investigating ethnicity effects on transport mode choices (e.g. Harms 2007) our results demonstrate that people with a non-western ethnicity cycle less and use the public transport more than native Dutch. Moreover, it appears that this is especially true for non-western elderly, indicating the importance of public transport to non-western elderly. In congruence to Mercado and Páez (2009), household size does matter, especially to the elderly. Elderly living in larger households walk, cycle, and use public transport significantly more than those living in smaller households. In contrast, for non-elderly household size is only significant for bicycle use. A positive effect of higher education on public transport usage, as found by Schwanen et al. (2001), could only be statistically confirmed for the non-elderly. Also household income has neither for the elderly, nor for the non-elderly, a significant effect on transport mode choices. However, differences between richer and poorer elderly may very well exist, but are likely mediated by differences in access to different transport modes. As expected, for both the elderly and non-elderly the most important transport mode determinants are transport resources on the household level. In congruence to Schwanen et al. (2001), for both the elderly and nonelderly, car ownership has an important negative effect and public transport card ownership an important positive effect on the use of all transport modes other than the car. Bicycle ownership positively affects elderly cycling and non-elderly walking and cycling compared to the car.

Of the health attributes, obesity is associated with significant reductions in walking and cycling amongst non-elderly, although causality of the relationship is difficult to establish. Disability has an important additional effect on transport mode choices amongst the elderly, which articulates the existence of within elderly variation in mobility patterns. Elderly constrained by disabilities in daily life, walk and use the public transport less, while being more often dependent on the car, and possibly on accompanying relatives or friends to chauffeur them.

When looked at trip characteristics, distance appears to be an important factor. For both the elderly and non-elderly, shorter distances are significantly more likely performed by bicycle and especially by foot, while long distances are significantly more likely performed by car and especially the public transport. However, when looked at the parameter coefficients and $z$-scores, the magnitude of distance effects is larger for the elderly. This may be explained by biological constraints or difficulties to walk and cycle longer distances with increasing age. As such, it may also reflect a higher dependency of the elderly on the car and public transport for longer distance trips. With regard to trip motives, both elderly and non-elderly are more likely to travel by car when travelling for leisure, and by foot, bicycle and public transport when travelling for works/study, errands and social visits. In addition, elderly transport mode choices are strongly related to whether they are travelling alone or in companion. When travelling in companion, elderly are more likely to do this by car, and 
less likely to cycle, walk or use the public transport. In comparison, non-elderly, when travelling in companion, are also more likely to do this by car and less likely to do this by bicycle, however they are not significantly less likely to do this by foot or public transport. Elderly transport mode choices do not differ significantly between weekdays and weekends. In this they differ from younger age cohorts who travel significantly less by public transport during the weekend.

From the built environmental attributes, address density has a significant positive effect on public transport usage over to the car, for the non-elderly, but even more so for the elderly. This could be related to better access to public transport in higher density areas, which could be of particular importance to the elderly, who may have a limited ability to reach stations and make transfer connections. Address density has a significant negative effect on elderly's likelihood to cycle compared to the car, while this effect is not observed for younger age cohorts. High-density areas may be experienced as less attractive as they feature busy and fast traffic, which could particularly deter elderly cyclists. This finding is intertwined with the significant positive effect of green space, which could be an indicator for a more quiet and attractive environment for elderly cycling. Finally, building diversity positively affects walking compared to the car for both elderly and non-elderly. A likely explanation could be the proximity of facilities as a result of mixed use, which makes walking a viable option, especially for elderly.

As transport decisions are influenced by weather conditions (Helbich et al. 2014), the models are adjusted in this respect. Both for the elderly and non-elderly, daily maximum air temperature has a significant positive effect on cycling in comparison to the car, but it leaves walking and public transport use largely unaffected. Precipitation sum, while having an important significant negative effect on non-elderly cycling, has no significant effect on elderly transport mode choices. Wind speed has no significant effect on transport mode choices, both for the elderly and non elderly. Snow cover increases the relative share of elderly walking. This does necessarily mean that elderly walk more. A more likely explanation is that snow deters some elderly to drive (the reference category), and perhaps stay closer to the home.

Figure 3 provides the descriptive results of a supplementary analysis of the impact of marginally occurring extreme weather events on elderly and non-elderly stated transport mode adaptations. As observed earlier for trip cancellations, extreme weather events affect
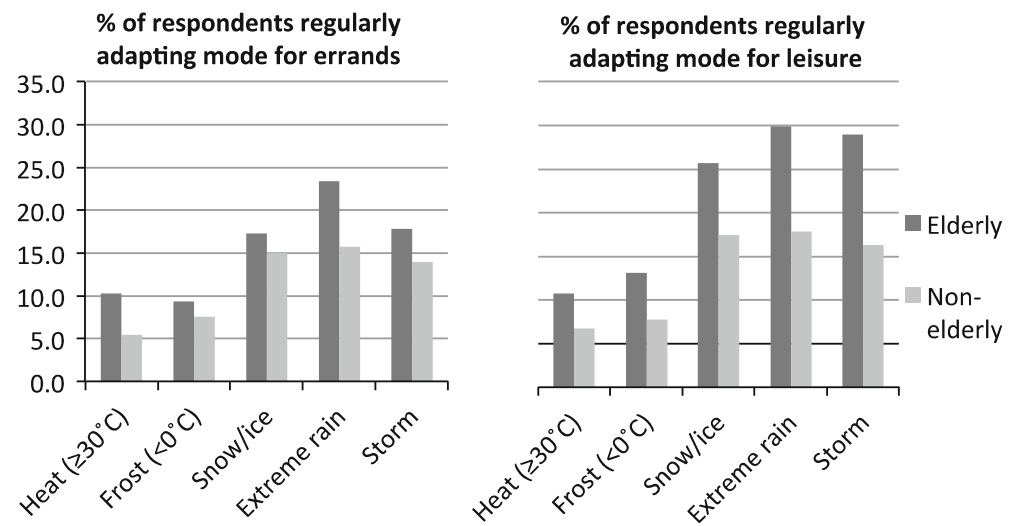

Fig. 3 Impact of extreme weather on stated transport mode adaptations 
a larger share of elderly in their errands and leisure transport mode choices than nonelderly. Especially snow/ice, extreme rain and storm make the elderly to switch transport modes. These effects are stronger for leisure than for errands trips.

\section{Conclusions}

In most western and several non-western societies, in particular in densely populated urban regions, demographic ageing presents major challenges to the transport sector to quantitatively absorb the induced elderly mobility demand, while at the same time qualitatively catering for the specific mobility needs that elderly require. In this context, this paper addresses and unites several issues currently underexplored in elderly mobility research: (a) an integrative investigation of both transport mode choices and trip making; (b) a direct comparison with non-elderly age cohorts; (c) an investigation of within-elderly variation in mobility based on socio-demographics and health attributes; (d) an investigation of physical and natural elements of the built environment on a neighbourhood level, and (e) an analysis of normal and extreme weather characteristics on elderly mobility. Drawing on six-day travel diary data amongst 945 respondents in Greater Rotterdam, the Netherlands, this paper analyses the effects of socio-demographics and trip, urban form and weather attributes on daily trip frequencies and transport mode choices utilizing zeroinflated negative binomial and multinomial logistic models. Multivariate mobility analyses are complemented by stated adaptation analyses of the effects of weather extremes.

Our results indicate differences between the elderly and non-elderly regarding: (a) overall travel frequencies (elderly travel less) and transport mode choices (elderly walk more and use the car less), and (b) the socio-demographic, trip, urban form and weather determinants underlying the travel behaviour within both groups. When looked at sociodemographics, age and gender have no significant effect on within-elderly trip frequencies. However, women, especially elderly women, are more dependent on walking, cycling and the public transport, while men more often use the car. Elderly with a non-western ethnicity travel less in general, and less by car and bicycle in particular-both to the benefit of public transport. Education and income effects on elderly mobility are relatively little, but may be mediated by transport resources. Car ownership is positively and public transport card membership negatively associated with elderly car use compared to all other transport modes. Bicycle ownership is positively associated with elderly cycling shares and elderly trip making in general, perhaps as an indicator of general health, but nevertheless highlighting the importance of cycling to the Dutch elderly. Regarding health attributes, disability reduces trip frequencies for the elderly and non-elderly, while obesity is negatively associated with active transport mode usage amongst non-elderly (but not amongst the elderly).

Regarding spatiotemporal trip attributes, elderly show similar trip frequencies over week- and weekend days (higher frequencies on weekdays), and transport mode choices according to trip motives (higher use of motorized modes for leisure) as non-elderly. Also, both subsamples report increased usage of motorized over active transport modes with increasing trip distance. However, this effect appears stronger for the elderly, which could be explained by physiological limitations or slower speeds regarding the use of active modes. Our results indicate that compact designs with high address densities and mixed land uses stimulate public transport usage and walking respectively, especially amongst the elderly. Possibly, the shorter distances to services and better public transport connections 
are of particular importance to the elderly. In contrast, the elderly cycle less in higher density urban areas with a lack of green, possibly related to the fast pace of busy inner-city traffic.

Weather also has differential effects on the elderly and non-elderly. Higher air temperature has no positive effect on elderly trip making as it does for the non-elderly. In congruence to existing research (e.g. Tuomaala et al. 2013), our stated extreme weather adaptation results show that this is most likely related to the elderly's higher heat sensitivity. Precipitation sum and snow cover have a trip-reducing effect on the elderly not observed for the non-elderly. This is possibly explained by higher weather-sensitiveness of the elderly, although it should be noted that non-elderly participate more often in utilitarian trips (e.g. for work) that are less easy to reschedule in preference to the weather. While negatively affecting active open-air mode usage for younger age cohorts, normal variations in precipitation sum and snow cover have no significant effect on elderly mode choices. When looked at weather extremes, however, elderly mode choices, as well as trip frequencies, are particularly affected by snow/ice, heavy rain and storm, as compared to nonelderly.

Policy makers who face the challenge to cope with demographic ageing, are advised to take into account the heterogeneity in mobility responses described above: not only between elderly and non-elderly, but especially also within the elderly subsample-for instance when designing policies or marketing campaigns to support walking, cycling or the use of public transport. For urban planners our results show that the implementation of compact urban land use designs, with higher densities, mixed building usages, and shorter distances to services and public transport, has the ability to reduce car use amongst the elderly population. This could have potential physical and mental health benefits to the elderly, as well as accessibility and environmental benefits to society. However, an important remaining challenge is to improve cycleability in densely populated areas, which appears from our results to be a far more prominent issue for the elderly than for the nonelderly population. Another important challenge is climate change, especially in cities where urban heat islands may proliferate due to higher densities and a lack of natural materials (e.g. Stewart and Oke 2012). In this context it is crucial to provide enough shading and natural cooling in residential environments and along active transport infrastructures, particularly in areas with large shares of more heat-sensitive elderly (e.g. Díaz et al. 2002; Tuomaala et al. 2013).

Further research is recommended to advance the here-documented knowledge on elderly mobility in several directions. This paper provides a rough estimation of the effects of urban and natural form on elderly mobility. However, more quantitative and qualitative studies are required to investigate the effects of urban environments and processes on elderly mobility in more detail (e.g. in relation to the quantity and quality of public transport, walking and cycling infrastructure, distances to services, specific types of green space), on smaller spatial scales (e.g. on a block or street level) and in more dynamic ways (e.g. while paying attention to the interactions with rhythms in traffic, pollutants and noises). These could be connected to more detailed global positioning system-tracked mobility data on a route level. Additionally, research could further investigate the use of transport modes neither covered by this (due to limitations of the data) nor by most existing research, to provide a more inclusive overview of elderly mobility and a more elaborative insights into the (in)dependency of elderly in their mobility. Examples may include the use of electric bicycles, mobility scooters, or (powered) wheelchairs, all of which provide spatial, safety as well as legal challenges when embedded in existing infrastructures (e.g. 
Requejo et al. 2015; Harris et al. 2015). Finally, while most existing elderly mobility studies, including this study, look at elderly mobility in western societies, more research is required to investigate the effects in newly industrialised or developing countries (e.g. Yang et al. 2014b; Olawole and Aloba 2014).

Open Access This article is distributed under the terms of the Creative Commons Attribution 4.0 International License (http://creativecommons.org/licenses/by/4.0/), which permits unrestricted use, distribution, and reproduction in any medium, provided you give appropriate credit to the original author(s) and the source, provide a link to the Creative Commons license, and indicate if changes were made.

\section{References}

Alsnih, R., Hensher, D.A.: The mobility and accessibility expectations of seniors in an aging population. Transp. Res. Part A 37, 903-916 (2003). doi:10.1016/S0965-8564(03)00073-9

Arentze, T.A., Timmermans, H.J.P., Jorritsma, P., OldeKalter, M.J., Schoenmakers, A.: More gray hair- but for whom? Scenario-based simulations of elderly activity travel patterns in 202. Transportation 35, 613-627 (2008). doi:10.1007/s11116-008-9170-z

Banister, D., Bowling, A.: Quality of life for the elderly: the transport dimension. Transp. Policy 11, 105-115 (2004). doi:10.1016/S0967-070X(03)00052-0

Binder, E.F., Schlechtman, K.B., Ehsani, A.A., Steger-May, K., Brown, M., Sinacore, D.R., et al.: Effects of exercise training on frailty in community-dwelling older adults: results of a randomized, controlled trial. J. Am. Geriatr. Soc. 50, 1921-1928 (2002)

Böcker, L., Thorsson, S.: Integrated weather effects on cycling shares, frequencies and durations in Rotterdam, the Netherlands. Weather Clim. Soc. 6, 468-481 (2014). doi:10.1175/WCAS-D-13-00066.1

Böcker L, Dijst M, Faber J (2014) Weather, transport mode choices and emotional travel experiences. In: Böcker L. (eds.) Climate, Weather and Daily Mobility: Transport Mode Choices and Travel Experiences in the Randstad Holland. Faculty of Geosciences, Utrecht University. Dissertation. ISBN: 978-94-6203-736-6

Böcker, L., Dijst, M., Prillwitz, J.: Impact of everyday weather on individual daily travel behaviours in perspective: a literature review. Transport Rev. 33, 71-91 (2013). doi:10.1080/01441647.2012.747114

Borst, H.C., de Vries, S.I., Graham, J.M.A., van Dongen, J.E.F., Bakker, I., Miedema, H.M.E.: Influence of environmental street characteristics on walking route choice of elderly people. J. Environ. Psychol. 29, 477-484 (2009). doi:10.1016/j.jenvp.2009.08.002

Collia, D.V., Sharp, J., Giesbrecht, L.: The 2001 national household travel survey: a look into the travel patterns of older Americans. J. Saf. Res. 34, 461-470 (2003). doi:10.1016/j.jsr.2003.1.001

Currie, G., Delbosc, A.: Exploring public transport usage trends in an ageing Population. Transportation 37, 151-164 (2009). doi:10.1007/s11116-009-9224-X

Delbosc, A., Currie, G.: Exploring the relative influences of transport disadvantage and social exclusion on well-being. Transp. Policy 18, 555-562 (2011). doi:10.1016/j.tranpol.2011.01.011

Díaz, J., García, R., Velázquez de Castro, F., Hernández, E., López, C., Otero, A.: Effects of extremely hot days on people older than 65 years in Seville (Spain) from 1986 to 1997. Int. J. Biometeorol. 46, 145-149 (2002). doi:10.1007/s00484-002-0129-z

Dienst Gezondheid, Jeugd (2014) Bevolkingsprognose. http://www.dienstgezondheidjeugd.nl/ toekomstverkenning/toekomstverkenning/bevolking-leefomgeving/bevolkingsprognose. Accessed 6 Mar 2015

Donaghy, K., Rudinger, G., Poppelreuter, S.: Societal trends, mobility behaviour and sustainable transport in Europe and North America. Transport Rev. 24, 679-690 (2004). doi:10.1080/0144164042000292461

Dutch Meteorological Institute (2013) Publically Available Weather Records. http://www.knmi.nl/ klimatologie/. Accessed 3 Mar 2014

European Commission (2014) The 2015 Ageing Report: Underlying Assumptions and Projection Methodologies. Joint Report prepared by the European Commission (DG ECFIN) and the Economic Policy Committee (AWG). doi:10.2765/76255

Figueroa, M.J., Nielsen, T.A.S., Siren, A.: Comparing urban form correlations of the travel patterns of older and younger adults. Transp. Policy 35, 10-20 (2014)

Gómez, L., Parra, D.C., Buchner, D., Brownson, R.C., Sarmiento, O.L., Pinzón, J.D., Ardila, M., Moreno, J., Serrato, M., Lobelo, F.: Built Environment Attributes and Walking Patterns Among the Elderly Population in Bogotá. Am. J. Prev. Med. 38, 592-599 (2010). doi:10.1016/j.amepre.201.02.005 
Hall, K.S., McAuley, E.: Individual, social environmental and physical environmental barriers to achieving 10000 steps per day among older women. Health Educ. Res. 25, 478-488 (2010). doi:10.1093/her/ cyq019

Harms, L.: Mobility among ethnic minorities in the urban Netherlands. Urban Mobility and Social Inequity.J. Urban Stud. 46(2) http://www.difu.de/en/publikationen/german/mobility-among-ethnicminorities-in-the-urban-netherlands.html (2007). Accessed 11 Jan 2016

Harper, S.: Economic and social implications of aging societies. Science 31, 587-591 (2014). doi:10.1126/ science. 1254405

Harris, F., Yang, H.Y., Sanford, J.: Physical environmental barriers to community mobility in older and younger wheelchair users. Topics Geriatr. Rehabil. 31(1), 42-51 (2015). doi:10.1097/TGR. 0000000000000043

Haustein, S.: Mobility behavior of the elderly: an attitude-based segmentation approach for a heterogeneous target group. Transportation 39(6), 1079-1103 (2012)

Haustein, S., Siren, A.K.: Seniors' unmet mobility needs-how important is a driving licence? J. Transport Geogr. 41, 45-52 (2014). doi:10.1016/j.jtrangeo.2014.08.001

Helbich, M., Böcker, L., Dijst, M.: Geographic heterogeneity in cycling under various weather conditions: evidence from greater Rotterdam. J. Transport Geogr. 38, 38-47 (2014). doi:10.1016/j.jtrangeo.2014.05.009

Hess, D.B.: Access to public transit and its influence on ridership for older adults in two US cities. J. Transport Land Use 2(1), 3-27 (2009). doi:10.5198/jtlu.v2i1.11

Hildebrand, E.D.: Dimensions in elderly travel behaviour: a simplified activity-based model using lifestyle clusters. Transportation 30(3), 285-306 (2003)

Hjorthol, R.J.: Winter weather-an obstacle to older people's activities? J. Transport Geogr. 28, 186-191 (2013). doi:10.1016/j.jtrangeo.2012.09.003

Hjorthol, R.J., Levin, L., Sirén, A.: Mobility in different generations of older persons: the development of daily travel in different cohorts in Denmark, Norway and Sweden. J. Transport Geogr. 18, 624-633 (2010). doi:10.1016/j.jtrangeo.201.03.011

Jorritsma P., Kalter M.O.: Grijs op reis. Over de mobiliteit van ouderen. Kennisinstituut voor Mobiliteitsbeleid Den Haag. http://www.rijksoverheid.nl/documenten-en-publicaties/rapporten/2008/ 11/20/grijs-op-reis-over-mobiliteit-van-ouderen.html (2008). Accessed 3 Mar 2014

Kemperman, A.D.A.M., Timmermans, H.J.P.: Green spaces in the direct living environment and social contacts of the aging population. Landsc. Urban Plan. 129, 44-54 (2014). doi:10.1177/ 0013916512466662

Kim, S.: Assessing mobility in an aging society: personal and built environment factors associated with older people's subjective transportation deficiency in the US. Transp. Res. Part F 14, 422-429 (2011)

Kim, S., Ulfarsson, G.F.: Travel mode choice of the elderly: effects of personal, household, neighborhood, and trip characteristics. Transp. Res. Rec. 1894(1), 117-126 (2004)

Li, H., Raeside, R., Chen, T., McQuaid, R.W.: Population ageing, gender and the transportation system. Res. Transp. Econ. 34, 39-47 (2012). doi:10.1016/j.retrec.2011.12.007

Lord, D., Mannering, F.: The statistical analysis of crash-frequency data: a review and assessment of methodological alternatives. Transp. Res. Part A 44, 291-305 (2010). doi:10.1016/j.tra.201.02.001

Marrattoli, R.A., de Leon, C.F.M., Glass, T.A., Williams, C.S., Cooney, L.M., Berkman, L.F.: Consequences of driving cessation: decreased out-of-home activity levels. J. Gerontol. Soc. Sci. 55, 334-340 (2000). doi:10.1093/geronb/55.6.S334

Mercado, R., Páez, A.: Determinants of distance traveled with a focus on the elderly: a multilevel analysis in the Hamilton CMA, Canada. J. Transport Geogr. 17, 65-76 (2009). doi:10.1016/j.jtrangeo.2008.04.012

Mercado, R., Páez, A., Newbold, K.B.: Transport policy and the provision of mobility options in an aging society: a case study of Ontario, Canada. J. Transport Geogr. 18(5), 649-661 (2010). doi:10.1016/j. jtrangeo.2010.03.017

Metz, D.: Transport policy for an ageing population. Transport Reviews 23, 375-386 (2003). doi:10.1080/ 0144164032000048573

Michael, Y., Beard, T., Choi, D., Farquhar, S., Carlson, N.: Measuring the influence of built neighborhood environments on walking in older adults. J. Aging Phys. Act. 14, 302-312 (2006)

Netherlands Environmental Assessment Agency (2013) VergrijzingenRuimte: Gevolgenvoor de woningmarkt, vrijetijdsbesteding, mobiliteitenregionaleeconomie. Den Haag: Planbureauvoor de Leefomgeving (PBL). ISBN: 978-94-91506-41-3

Newbold, K.B., Scott, D.M., Spinney, J.E.L., Kanaroglou, P., Páez, A.: Travel behavior within Canadas older population: a cohort analysis. J. Transport Geogr. 13, 340-351 (2005). doi:10.1016/j.jtrangeo. 2004.07.007

Noble B (2000) Travel characteristics of older people. In: Department of the Environment, Transport and the Regions (eds.) Transport Trends 2000. London. 9-25 
Okola AR, Walton CM (2003) Intelligent Transportation Systems to Improve Elderly Persons' Mobility and Decision Making within Departure Time Choice Framework, Southwest Regional University Transportation Centre, University of Austin, Texas, Research Report SWUTC/03/167531-1

Olawole, M.O., Aloba, O.: Mobility characteristics of the elderly and their associated level of satisfaction with transport services in Osogbo, Southwestern Nigeria. Transp. Policy 35, 105-116 (2014). doi:10. 1016/j.tranpol.2014.05.018

Oxley, J., Whelan, M.: It cannot be all about safety: the benefits of prolonged mobility. Traffic Inj Prev. 9, 367-378 (2008). doi:10.1080/15389580801895285

Páez, A., Scott, D., Potoglou, P., Kanarogou, P., Newbold, K.B.: Elderly mobility: demographic and spatial analysis of trip making in the Hamilton CMA, Canada. Urban Stud. 44, 123-146 (2007). doi:10.1080/ 00420980601023885

Ravulaparthy, S.K., Goulias, K.G., Yoon, S.Y., Polydoropoulou, A.: Transport mobility, activity and subjective well-being. In: Roorda, M., Miller, E. (eds.) Travel Behaviour Research: Current Foundations, Future Prospect. Lulu Publishers, Raleigh (2013)

RegioAtlas (2014) COROP Subregio's. http://www.regioatlas.nl/indelingen/indelingen_indeling/t/corop_ subregio_s. Accessed 20 May 2014

Requejo, P.S., Furumasu, J., Mulroy, S.J.: Evidence-Based Strategies for Preserving Mobility for Elderly and Aging Manual Wheelchair Users. Topics Geriatr. Rehabil. 31(1), 26-41 (2015). doi:10.1097/TGR. 0000000000000042

RET (2015) Vrijreizenvoor 65-plussers. http://www.ret.nl/service-en-verkoop/reisproducten-en-tarieven/ vrij-reizen-voor-65-plussers.html. Accessed 13 Mar 2015

Rosenbloom, S.: Sustainability and automobility among the elderly: an international assessment. Transportation 28, 375-408 (2001). doi:10.1023/A:1011802707259

Rosenbloom S (2004) Mobility of the elderly: good news and bad news. In: Transportation in an Aging Society, A Decade of Experience, Conference Proceedings 27. Washington, D.C.: Transportation Research Board. 3-21. ISBN: 0-309-07745-1

Sabir, M.: Weather and travel behaviour. VU University, Amsterdam (2011)

Scheiner, J.: Does the car make elderly people happy and mobile? Settlement structures, car availability and leisure mobility of the elderly. Eur. J. Transp. Infrastruct. Res. 6(2), 151-172 (2006)

Schmöcker, J., Quddus, M.A., Noland, R., Bell, M.G.H.: Estimating trip generation of elderly and disabled people: analysis of London data. Transportation 1924, 9-18 (2005). doi:10.3141/1924-02

Schmöcker, J., Quddus, M.A., Noland, R.B., Bell, M.G.H.: Mode choice of older and disabled people: a case study of shopping trips in London. J. Transp. Geogr. 16, 257-267 (2008). doi:10.1016/j.jtrangeo.2007.07.002

Schwanen, T., Dijst, M., Dieleman, F.M.: Leisure trips of senior citizens: determinants of modal choice. Tijdschr. voor Econ. Soc. Geogr. 92, 347-360 (2001)

Schwanen, T., Páez, A.: The mobility of older people-an introduction. J. Transport Geogr. 18, $591-595$ (2010). doi:10.1016/j.jtrangeo.201.06.001

Siren, A., Haustein, S.: Baby boomers' mobility patterns and preferences: what are the implications for future transport? Transp. Policy 29, 136-144 (2013)

Stewart, I.D., Oke, T.R.: Local climate zones for urban temperature studies. Bull. Am. Meteorol. Soc. 93(12), 1879-1900 (2012). doi:10.1175/BAMS-D-11-00019.1

Tuomaala P, Holopainen R, Piira K, Airaksinen M (2013) Impact of individual characteristics—such as age, gender, BMI, and fitness-on human thermal sensation. In: Proceedings of the 13th Conference of the International Building Performance Simulation Association, Chambéry. http://ibpsa.org/proceedings/ BS2013/p_2240.pdf. Accessed 6 Jun 2014

Van den Berg, P., Arentze, T., Timmermans, H.: ), Estimating social travel demand of senior citizens in the Netherlands. J. Transport Geogr. 19, 323-331 (2011). doi:10.1016/j.jtrangeo.201.03.018

Visser, M., Pluijm, S.M., Stel, V.S., Bosscher, R.J., Deeg, D.J.: Physical activity as a determinant of change in mobility performance: the Longitudinal Aging Study Amsterdam. J. Am. Geriatr. Soc. 50(11), 1774-1781 (2002). doi:10.1046/j.1532-5415.2002.50504.x

Vuong, Q.H.: Likelihood ratio tests for model selection and non-nested hypotheses. Econometrica 57(2), 307-333 (1989). doi:10.2307/1912557

Waldorf, B.: Automobile reliance among the Elderly: race and Spatial context effects. Growth Change 34, 175-201 (2003). doi:10.1111/1468-2257.00213

Strawbridge, W.J., Deleger, S., Roberts, R.E., Kaplan, G.A.: Physical activity reduces the risk of subsequent depression for older adults. Am. J. Epidemiol. 156(4), 328-334 (2002). doi:10.1093/aje/kwf047

Wong, B.Y.M., Faulkner, G., Buliung, R.: GIS measured environmental correlates of active school transport: a systematic review of 14 studies. Int. J. Behav. Nutr. Phys. Act. 8(39), 1479-5868 (2011). doi:10.1186/ 1479-5868-8-39 
Wooldridge, JM (2002) Econometric Analysis of Cross Section and Panel Data. Cambridge, MA: MIT Press. ISBN-13: 978-0-262-23258-6

Yang, D., Timmermans, H., Grigolon, A.: Exploring heterogeneity in travel time expenditure of aging populations in the Netherlands: results of a CHAID analysis. J. Transport Geogr. 33, 170-179 (2014a). doi:10.1016/j.jtrangeo.2013.10.002

Yang, W.Y., Liao, Y.M., Zheng, S.Y.: Study on the characteristics of the bus trip of the elders in Nanjing. Appl. Mech. Mater. 587, 1840-1853 (2014b). doi:10.4028/www.scientific.net/AMM.587-589.1840

Lars Böcker is a postdoctoral researcher at the department of Sociology and Human Geography at the University of Oslo. His current research is on climate, weather and mobility, smart cities, urban health, sustainable accessibility, low energy mobility, urban metabolism, and the sharing economy.

Patrick van Amen was a researcher at the Department of Human Geography and Spatial Planning, Utrecht University, The Netherlands. His research was about mobility behaviour.

Marco Helbich is an Assistant Professor at the Department of Human Geography and Spatial Planning, Utrecht University, The Netherlands. His research interests are in health, active transportation, and the built environment, among others. 